J. Lake Sci. (湖泊科学) , 2015, 27(4):679-685

DOI $10.18307 / 2015.0416$

(C) 2015 by Journal of Lake Sciences

\title{
基于鱼类生物完整性指数的广东鉴江流域环境质量评估
}

\author{
郜星晨, 章 群*, 韩博平, 薛 丹, 宫亚运, 曹 艳
}

(暨南大学水生生物研究中心,广州 510632 )

\begin{abstract}
摘 要: 根据鉴江流域 21 个观测点鱼类调查所收集的数据, 结合历史资料的记录, 初步构建基于鱼类生物完整性评价的 26 个初选指标, 并根据指标属性分类进行初笁, 对 10 个通过的候选指标进行分布范围、判别能力和 Pearson 相关性分析, 确定了由总的种类数占期望值的百分比、鲤科鱼类占总种类数的百分比、鳑鲏亚科鱼类占总种类数的百分比、耐受性强 鱼类占总种类数的百分比和产漂流性卵鱼类占总种类数的百分比共 5 个主评指标组成的生物完整性指数体系,并用于鉴 江流域部分河段的生态健康评价. 结果表明,凌江鱼类完整性相对较好,罗江一般,平定水、袂花江和鉴江干流较差,小东 江最差; 鉴江流域大多数河段的综合健康状态处于较差状态, 需要对鉴江流域进行生态修复以达到相对健康状态. 评价 结果与河流受人为干扰的实际情况相吻合,研究构建的评价体系可供周边地区使用和借鉴.
\end{abstract}

关键词: 生物完整性指数;鱼类;指标体系;鉴江流域

\section{Environmental quality assessment of Jian River Basin(Guangdong) based on fish biotic integrity index}

GAO Xingchen, ZHANG Qun, HAN Boping, XUE Dan, GONG Yayun \& CAO Yan

(Research Center of Hydrobiology, Jinan University, Guangzhou 510632, P. R. China)

\begin{abstract}
Based on the data collected from 21 sites in Jian River Basin and historical data, 26 candidate metrics representing attributes of fish assemblage were screened. Of which, tenmetrics passed the initial selection, then the analyses of index value distribution, discrimination ability and Pearson correlation were performed, finally 5 major indicators were used for the biotic integrity index system to assess the environmental quality of Jian River Basin, which are percent of total number of species in expectation, percent of cyprinid species, percent of Acheilognathinae species, percent of tolerant species, percent of species with pelagic eggs. It suggested that the fish-based biological integrity index was good in Ling River, fair in Luo River, poor in Pingding River, Meihua River and the main stream, and Xiaodong River was the worst. As comprehensive health status of rivers was in the worse state, certain measures should be taken for ecological restoration to the relatively healthy state. The assessments were consistent with the actual situation of human disturbance in this river drainage. The established fish biotic integrity index in this study could be used to assess environmental quality or used as reference for rivers in adjacent regions.
\end{abstract}

Keywords: Biotic integrity index; fish; index system; Jian River Basin

河流生态系统具有调节气候、改善生态环境以及维护生物多样性等功能,但容易受到人类活动的干扰 和环境污染的影响. 长期以来对生态环境的评价主要依赖于物理、化学指标以及对生物个体与种群跟踪监 测的环境评价,但近年来已扩展为对整个生态系统 “健康” 状态的生态评估, 强调从生态系统的角度客观反 映河流的健康状况 ${ }^{[1]}$. 生物完整性(biological integrity) 是生物群落自身所具有的维持自身平衡、保持结构完 整和适应环境变化的能力 ${ }^{[2]}$,包含该群落在一个地区的天然栖息地中所具有的种类组成、多样性和功能结 构特征. 因此生物完整性不仅是生物自身生存状态的体现,也是对生物生存的环境质量的一种反映. 生物

* 水利部河湖健康评估广东省试点项目 (2013001) 和中央高校基本科研业务费专项资金项目 $(21613105,21611426)$ 联合资助. 2014-08-11 收稿;2014-12-04 收修改稿. 郜星晨(1989 ), 男, 硕士研究生; E-mail:13039829682@ 126. com.

** 通信作者;E-mail: zhangqunjnu@ gmail. com. 
完整性指数 (index of biological integrity, IBI) 评价体系是通过对生态系统中某一类群落的物种组成、多样性 及功能结构方面进行分析, 将其与相应的标准体系比较, 然后根据分类指标评出选定区域的优劣 ${ }^{\left[{ }^{[3]}\right.}$. Karr 等 最早以鱼类为研究对象, 建立了采用 $I B I$ 评价河流健康状况的方法 ${ }^{[2]}$; 此后该方法不断完善, 评价对象从冷 水性溪流扩展到暖水性溪流、湖泊、河流、河口、湿地等不同类型的水体 ${ }^{[4]}, I B I$ 的概念和方法也被广泛应用 于大型底栖动物、藻类和浮游生物等水生生物类群. 由于鱼类在水体生态系统中分布范围广、营养等级高、 对水质变化反应灵敏 ${ }^{[5]}$, 因此最适合用于评估流域健康状况. 迄今在全球不同地区和类型的水体都有利用 鱼类成功构建不同类型的生物完整性评价体系的报道, 如 Bozzetti 等应用鱼类完整性评价巴西南部亚热带 地区河流健康状况 ${ }^{[6]}$, Schmitter-Soto 等利用鱼类完整性评价外来物种、富营养化及农药毒害对日本本州河 流健康状况的影响 ${ }^{[4]}$, 美国至少有 29 个州成功应用鱼类完整性评价河流健康状况 ${ }^{[4]}$. 目前国内基于 IBI 评 价研究还处在起步阶段, 大多以底栖无脊椎动物和葆类为研究对象, 基于鱼类完整性代表性研究仅见于郑 海涛对怒江中上游进行的评价 ${ }^{[3]}$; 刘明典等建立了适合长江中上游地区河流健康评价的鱼类生物完整性指 标体系 ${ }^{[7]}$; 裴雪姣等对辽河流域的健康进行评价分析等 ${ }^{[8]}$. 由于各个地区鱼类区系和河流自然状况不同, 评 价体系也存在较大差异 ${ }^{[9]}$, 因此应用于一个新的评价区域时需要因地制宜. 鉴江作为广东省第三大水系, 是 当地工农业及饮用水源的重要河流, 同时还兼顾防旱、发电等其它多种功能, 逐渐成为茂名、湛江两市经济 发展的命脉. 由于近年来水库及城镇建设等人为活动的干扰和损害, $1990 \mathrm{~s}$ 经过治理才有所好转, 但局部水 质污染依然严重 ${ }^{[10]}$, 其健康状态一直备受关注. 但目前鉴江流域生态环境健康状况仍没有完善的评估方 法, 周边地区也缺乏参考价值的鱼类完整性研究. 本研究以鉴江流域鱼类为研究对象, 旨在建立适合该地区 的 $I B I$ 评价指标体系, 并对该地区部分河段客观描述和评价, 以加强河流环境质量监测和管理, 为鉴江可持 续管理、区域生态环境建设提供科学依据.

\section{1 研究区与研究方法}

\section{1 研究区概况}

鉴江 $\left(21^{\circ} 15^{\prime} \sim 22^{\circ} 30^{\prime} \mathrm{N}, 110^{\circ} 20^{\prime} \sim 111^{\circ} 20^{\prime} \mathrm{E}\right)$ 发源于信宜县五里大山, 全长 $231 \mathrm{~km}$, 集水面积 $1668 \mathrm{~km}^{2}$, 流经信宜、高州、化州、茂名、电白、吴川等五县一市, 注人南海. 鉴江流域地貌较复杂, 是以丘陵为主, 山地、 丘陵、平原相结合的类型. 雨量充沛, 河网密度大, 年平均雨量大多在 $1600 \mathrm{~mm}$ 以上, 流域多年平均降水量为 $1820 \mathrm{~mm}$, 地区性差异大, 降雨多集中在 4-9 月, 约占年降雨量的 $85 \%$ 左右, 流域内有大中型水库 11 座. 鉴 江支流众多,其中集雨面积大于 $500 \mathrm{~km}^{2}$ 的有罗江、凌江、大井河、袂花江.

\section{2 评价河流 (河段)的选定与数据采集}

根据受人为影响类型和强度的不同,并结合可操作性和安全性原则 ${ }^{[11]}$, 确定鉴江干流、袂花江、罗江、凌 江、平定水和小东江 6 条河段 21 个观测点作为本研究的评价对象(图 1). 2013 年 4 月 24 日至 5 月 7 日和 2014 年 4 月 26 日至 5 月 17 日在调查河流的上、中、下游雇佣当地渔民,选取适合各河段的最高效捕捞工具采 集鱼类标本. 平定水和鉴江中下游为非涉水而过河流, 采用相同规格的电鱼船于夜间作业 $2 \mathrm{~h}$, 采样河段长度 不小于 $2 \mathrm{~km}$; 其他 4 条河流在调查河段中鱼群经常出没区域 (根据渔民经验判断) 设置网目为 $15 、 50 \mathrm{~mm}$ 两种 类型的粘网和地笼采样. 记录各观测点位置、鱼类物种数、个体数及鱼类体长体重, 并通过市场购买和访问调查 的方式作为鱼类种类调查的补充. 调查中不确定的种类用 $95 \%$ 的酒精固定后带回, 参考文献[12-13]进行鉴定.

\section{3 评价指标的设置及设置原则}

初选指标设置遵循全面性和适用性的原则, 基于鱼类的群落组成、耐污类型、营养结构及生境质量等生 物特征, 归类为种类组成和丰度、耐受性、营养结构、繁殖共位群、鱼类数量和健康状况等 5 个项目层指 标 ${ }^{[14]}$, 结合指标在野外采样过程中的数据特点, 在其下设置了对环境变化较为敏感的 26 个初选指标. 本研 究只将历史数据中种类大于 5 种的科或亚科作为分类类群指标, 以防止指标数据范围过小 ${ }^{[4]}$; 敏感型鱼类 的确定参照文献 $[3,13]$; 单位努力捕捞量所指的是在所调查河段使用适合该河段的最高效捕捞工具进行捕 捞时 ${ }^{[8]}$, 由单个捕捞工具在单位时间内 $(1 \mathrm{~h})$ 的渔获物个体数量, 设多个观测点的河段, 该河段的单位努力 捕捞量为各个观测点单位努力捕捞量的平均值 ${ }^{[15]}$.

\section{4 参照点的确定}

按观测点受人类活动干扰程度大小可分为无干扰样点、干扰极小样点和干扰样点, 其中无干扰样点和 


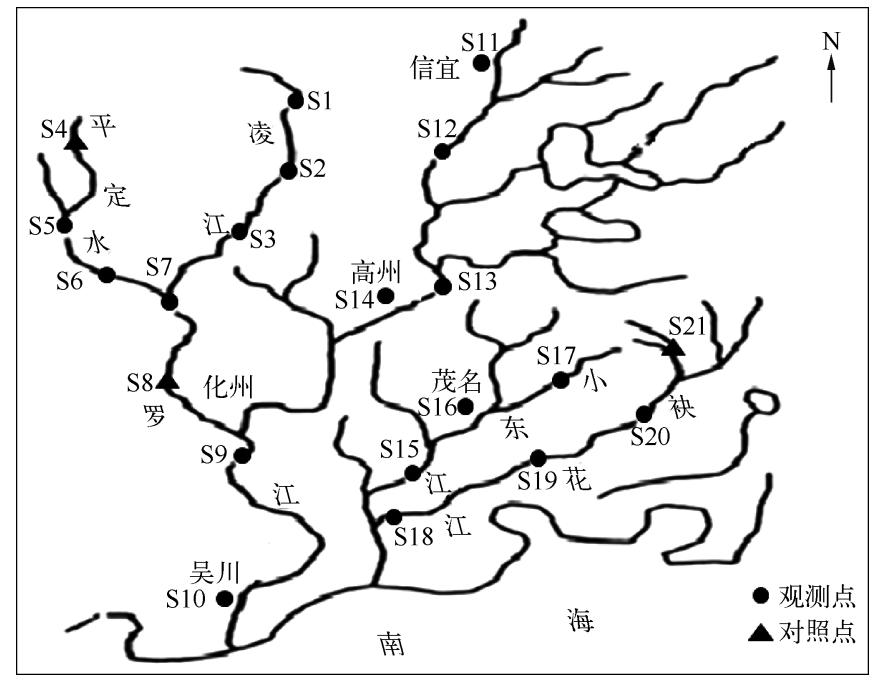

图 1 广东鉴江水系及观测点分布

Fig. 1 River systems and sampling sites in Jian River, Guangdong Province

干扰极小样点作为指标篮选过程中的参照点 ${ }^{[16]}$. 在目前人类活动的影响下, 不受干扰的河流几乎不存 在 ${ }^{[16]}$, 因此本研究尽可能以有历史数据的为参照点, 如不能使用历史数据的指标, 将选择受干扰较小的河段 作为参照点 ${ }^{[17]}$ : 选取上游无船舶航运影响河道中的 $\mathrm{S} 4$ 为平定水的参照点; 水质清澈、水生生物丰富的 S8 为 罗江的参照点; 人类活动较少的 S21 为袂花江的参照点.

\section{5 评价指标的设置及篮选原则}

最初 Karr 等确定的指标体系没有篮选过程, 在随后的研究中, 部分学者开始尝试多指标篮选 ${ }^{[3]}$, 本文采 用具有代表性的篮选方式, 根据指标属性分类进行篮选 ${ }^{[3]}$ : 种类数指标, 取消各观测点结果均小于 5 的指 标; 百分比指标, 取消各观测点之间的差异小于 $10 \%$ 的指标; 取消 $90 \%$ 以上观测点数值均为 0 的指标 ${ }^{[3,18]}$. 然后对候选指标依次进行分布范围检验、判别能力分析和候选指标相关性分析. 分布范围分析剔除可变动 范围比较窄、标准差大即参数值不稳定的候选指标 ${ }^{[4]}$. 根据 Barbour 的评价方法 ${ }^{[17]}$, 判别能力篮选是比较参 照点位和观测点在 $25 \%$ 75\% 分位数范围即箱体 $I Q$ (interquartile ranges) 的重叠情况. 分别赋予不同的值: 没 有重叠, $I Q=3$; 各自中位数值都在对方箱体范围之外, $I Q=2$; 仅 1 个中位数值在对方箱体范围之内, $I Q=1$; 各自中位数值都在对方箱体范围之内, $I Q=0$. 只有 $I Q \geqslant 2$ 的参数才能进一步分析. Pearson 相关性分析确定 指标间的信息重叠程度, $R>0$ 时参数正相关, $R<0$ 时参数负相关, $|R|<0.9$ 时候选指标才能通过篮选.

\section{6 赋值标准的确定}

期望值是各指标期望达到的最理想状态, 因此将 6 条河段各指标中最好的历史数据作为期望值, 用以 制定赋值标准. 总的种类数占期望值的百分比和耐受性强鱼类物种数百分比这两个指标无法使用历史数据 作为期望值, 以调查指标数据中最好的数据为期望值. 指标赋值参照 Karr 等的方法 ${ }^{[11]}$, 将各指标分为 $1 、 3 、 5$ 分 3 个层次: 5 分表示调查所得数据与期望值十分接近; 3 分属于中等; 1 分表示与期望值相差大. 为消除指 标数量造成的 $I B I$ 总分差异, 采用 Moyle 等的 $I B I$ 总分计算方法 ${ }^{[19]}$, 即: $I B I$ 总分 $=$ 各指标总分 $/$ 指标个数 $\times$ 12. 依据 Karr 等 ${ }^{[11]}$ 基于鱼类完整性划分河流的 6 个等级: 没有鱼 (0)、极差 (12 22)、差 (28 34)、一般 (40 44)、好( $48 \sim 52)$ 、极好 (58 60); 若某河流的 $I B I$ 总分介于两个评价等级的分值之间, 则该河流的鱼 类完整性评价为处于两个评价等级之间的水平.

\section{2 研究结果}

\section{1 初选指标的应用}

鉴江鱼类主要由鲤形目、鲇形目、鲇形目和合鰓鱼目组成. 两次野外采集到共约 4348 尾鱼,共计 6 
目 31 科 46 属 74 种, $90 \%$ 以上鱼类个体体长小于 $15 \mathrm{~cm}, 26$ 个初选指标数据采集处理结果见表 1 .

表 1 鱼类完整性初选指标及调查结果

Tab. 1 Candidate indices of fish integrity index and their results

\begin{tabular}{|c|c|c|c|c|c|c|c|c|}
\hline 项目层 & $\begin{array}{l}\text { 参数 } \\
\text { 缩写 }\end{array}$ & 指标层 & 鉴江 & 袂花江 & 罗江 & 凌江 & 平定水 & 小东江 \\
\hline \multirow[t]{16}{*}{ 种类组成和丰度 } & M1 & 渔获物鱼类总种类数 & 48.0 & 33.0 & 28.0 & 28.0 & 25.0 & 19.0 \\
\hline & M2 & 总的种类数占期望值的百分比 $/ \%$ & 76.1 & 76.2 & 77.8 & 87.5 & 83.3 & 84.0 \\
\hline & M3 & 鲤科鱼类物种数百分比/\% & 53.3 & 56.3 & 64.3 & 66.7 & 57.0 & 85.7 \\
\hline & M4 & 鳅科鱼类物种数百分比/\% & 2.2 & 3.1 & 3.6 & 0 & 4.0 & 4.8 \\
\hline & M5 & 平鲔鳅科鱼类物种数百分比/\% & 2.2 & 0 & 3.6 & 0 & 4.0 & 4.8 \\
\hline & M6 & 鲿科鱼类物种数百分比/\% & 4.4 & 0 & 7.1 & 4.8 & 8.0 & 0 \\
\hline & M7 & 雅罗鱼亚科鱼类物种数百分比/\% & 4.4 & 6.3 & 0 & 0 & 0 & 4.8 \\
\hline & M8 & 鲌亚科鱼类物种数百分比/\% & 8.9 & 9.4 & 17.9 & 19.0 & 16.0 & 9.5 \\
\hline & M9 & 野鲮亚科鱼类物种数百分比/\% & 6.7 & 3.1 & 10.7 & 9.5 & 8.0 & 9.5 \\
\hline & M10 & 鲃亚科鱼类物种数百分比/\% & 2.2 & 3.1 & 7.1 & 4.8 & 4.0 & 4.8 \\
\hline & M11 & 鮈亚科鱼类物种数百分比/\% & 11.1 & 9.4 & 10.7 & 19.0 & 8.0 & 9.5 \\
\hline & M12 & 鳑鮍亚科鱼类物种数百分比/\% & 2.2 & 6.3 & 10.7 & 14.3 & 4.8 & 4.0 \\
\hline & M13 & 上层鱼类物种数百分比/\% & 2.1 & 6.1 & 3.6 & 8.6 & 4.0 & 10.5 \\
\hline & M14 & 中上层鱼类物种数百分比/\% & 21.3 & 27.3 & 21.4 & 30.7 & 20.0 & 26.3 \\
\hline & M15 & 中下层鱼类物种数百分比/\% & 21.3 & 24.2 & 28.6 & 21.4 & 20.0 & 31.6 \\
\hline & M16 & 底层鱼类物种数百分比/\% & 55.3 & 42.4 & 46.4 & 39.3 & 56.0 & 31.6 \\
\hline \multirow[t]{2}{*}{ 耐受性 } & M17 & 耐受性强鱼类个体百分比/\% & 13.3 & 9.4 & 25.0 & 23.8 & 24.0 & 9.5 \\
\hline & M18 & 敏感型鱼类个体百分比/\% & 31.1 & 25.0 & 50.0 & 52.4 & 40.0 & 38.1 \\
\hline \multirow[t]{4}{*}{ 营养结构 } & M19 & 鱼食性鱼类个体百分比/\% & 36.4 & 23.1 & 22.7 & 16.7 & 28.0 & 25.0 \\
\hline & M20 & 植食性鱼类个体百分比/\% & 11.4 & 11.5 & 9.1 & 5.6 & 8.0 & 10.0 \\
\hline & M21 & 杂食性鱼类个体百分比/\% & 38.6 & 57.7 & 54.5 & 44.4 & 56.0 & 50.0 \\
\hline & M22 & 低栖动物食性鱼类个体百分比/\% & 13.6 & 7.7 & 13.6 & 15.0 & 8.0 & 33.3 \\
\hline \multirow[t]{2}{*}{ 繁殖共位群 } & M23 & 产粘性卵鱼类物种数百分比/\% & 56.3 & 68.8 & 69.6 & 57.9 & 58.3 & 72.7 \\
\hline & M24 & 产漂流性卵鱼类物种数百分比/\% & 43.7 & 31.2 & 30.4 & 42.1 & 41.7 & 27.3 \\
\hline \multirow[t]{2}{*}{ 鱼类数量和健康状况 } & M25 & 单位努力捕捞量 & 405 & 303 & 264 & 361 & 292 & 289 \\
\hline & M26 & 外表病变或畸变个体数量 & 3 & 2 & 0 & 0 & 1 & 0 \\
\hline
\end{tabular}

\section{2 指数的篩选}

初步篮选表明, M26 在各评价河段的调查结果均小于 5, M1、M4 M11、M13～M14、M19～M21、M25 在 各评价河段间的差异均小于 $10 \%$, 最终确定 10 个候选指标. 该 10 个候选指标分布范围适中,均通过了分布

表 26 个候选生物参数间的 Pearson 相关分析结果

Tab. 2 The correlation of Pearson on matrix of six candidate metrics

\begin{tabular}{ccccccc}
\hline 生物参数 & M2 & M3 & M12 & M17 & M22 & M24 \\
\hline M2 & 1 & & & & & \\
M3 & 0.566 & 1 & & & & \\
M12 & 0.491 & 0.222 & 1 & & & \\
M17 & 0.420 & -0.160 & 0.588 & 1 & & \\
M22 & 0.368 & $0.924^{* *}$ & -0.033 & -0.354 & 1 & \\
M24 & -0.164 & 0.033 & $-0.824^{*}$ & -0.363 & 0.289 & 1 \\
\hline
\end{tabular}

**表示差异极显著, $P<0.01 ; *$ 表示差异显著, $P<0.05$.
范围的篮选. 判别能力分析 M2、M3、 M12、M17、M22、M24 在观测点和参 照点具有显著差异, 对人为活动干扰 表现稳定的变化趋势进人下一轮分 析 (图 2). M3 与 M22 相关性显著, 其 余 $|R|$ 值均小于 0.9 (表 2), 考虑到鲤 科鱼类物种数百分比在 $I B I$ 研究中的 应用更为广泛 ${ }^{[15]}$, 最终确定了鉴江 流域 M2、M3、M12、M17、M24 共 5 个 基本的、易于量化的指标用以建立 IBI 指标体系. 


\section{3 综合评价结果}

根据指标的调查结果和评分标

准见表 3,6 条评价河段的鱼类完整性分值见表 4. 结果表明: 凌江鱼类完整性为好,多数指标均与期望值接 近, 反映该河流受人为干扰较少; 鉴江干流一般, 耐受性差的种类丧失、数量下降, 耐受力强的种类频度增加 使营养结构偏斜, 表明环境恶化的讯号; 小东江为极差, 鱼类资源量下降、生长和体质等指标下降, 种类减 少, 渔获物个体小型化, 耐受性强的杂食性种类增多, 可见小东江鱼类资源恶化, 河流受污染和破坏比较 严重.
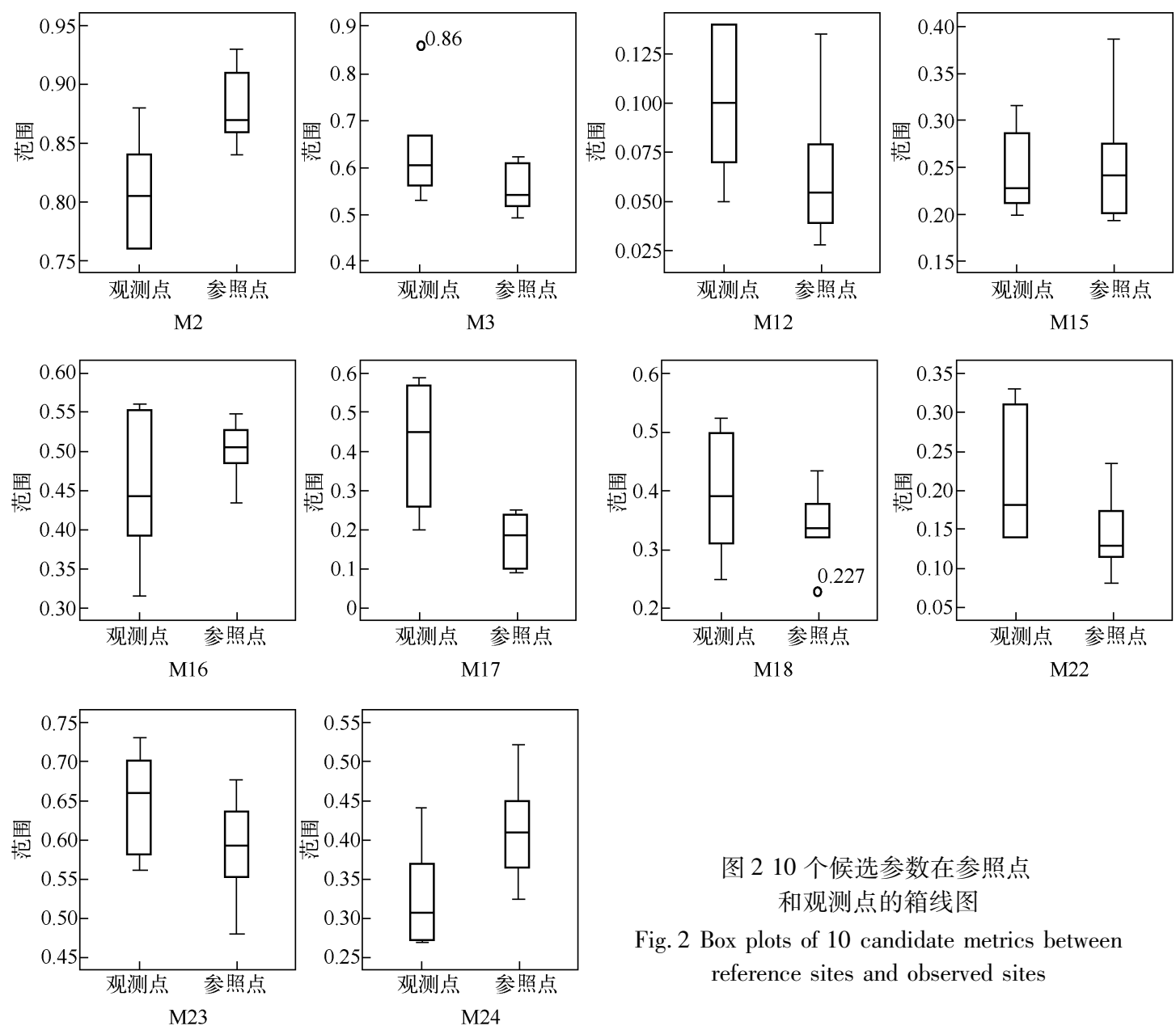

\section{图 210 个候选参数在参照点 和观测点的箱线图}

Fig. 2 Box plots of 10 candidate metrics between reference sites and observed sites

\section{3 讨论}

\section{1 评价结果与实际情况的符合程度}

评价结果表明,凌江鱼类完整性好,罗江一般,平定水、袂花江和鉴江干流差,小东江极差,鉴江大部分 河段介于“差”至“一般”之间,属于受干扰较多的河流. 小东江由于茂名炼油厂、化工厂等排放大量工业污 水以及市区人口激增和饮食业活跃带来的大量生活污水, 河段污染严重 ${ }^{[10]}$. 鉴江干流两岸是经济较发达的 地区, 捕捞强度过大,水利枢纽建设也对河流环境产生极大影响. 鉴江流域茂名市辖区内有 2 座大型水库, 即高州水库和罗坑水库, 对下游的河道、生态及地下水补给都会产生很大的负面影响; 袂花江靠近小东江, 面临无序挖沙牧垦、工农业及生活污染等问题; 罗江、平定水相对偏远, 经济落后, 受污染较小, 对生活污染 
有一定自净化能力. 根据刘家富对鉴江流域水质的监测报道 ${ }^{[20]}$ 和本课题组调查结果显示, 鉴江上游水质保 持良好, 为 I II 类; 干流及中下游河段尤其是高州城区、化州城区段水质下降严重, 支流罗江的断面未达 II 类目标水质, 小东江的镇盛、石碧断面水质均为超 $\mathrm{V}$ 类; 这与生物完整性评价结果基本一致, 说明针对鉴 江流域构建的鱼类完整性评价体系与传统理化指标检测具有很好的一致性, 较为客观地反映了河流健康状 况,对鉴江流域及周边地区开展河流健康评估研究有一定参考价值.

表 3 鱼类完整性指标赋值标准及对干扰的响应

Tab. 3 Scoring criteria of fish integrity index and response to disturbance

\begin{tabular}{|c|c|c|c|c|c|}
\hline \multirow{2}{*}{ 指标 } & \multirow{2}{*}{ 期望值 } & \multicolumn{3}{|c|}{ 赋值标准 } & \multirow{2}{*}{ 对干扰响应 } \\
\hline & & 1 & 3 & 5 & \\
\hline 总的种类数占期望值的百分比 M2/\% & 89 & $<77$ & $77 \sim 85$ & $>85$ & 下降 \\
\hline 鲤科鱼类物种数百分比 M3/\% & 53 & $>75$ & $58 \sim 75$ & $<58$ & 上升 \\
\hline 鳑鮍亚科鱼类物种数百分比 M12/\% & 15 & $<4.8$ & 4. $8 \sim 9$ & $>9$ & 下降 \\
\hline 耐受性强鱼类个体百分比 M17/\% & 26 & $<10$ & $10 \sim 24$ & $>24$ & 上升 \\
\hline 产漂流性卵鱼类物种数百分比 M24/\% & 45 & $<29$ & $29 \sim 42$ & $>42$ & 下降 \\
\hline
\end{tabular}

表 4 鱼类完整性的评分

Tab. 4 Scores of fish integrity

\begin{tabular}{lcccccc}
\hline 项目 & 鉴江 & 袂花江 & 罗江 & 凌江 & 平定水 & 小东江 \\
\hline 总的种类数占期望值的百分比 M2 & 1 & 1 & 3 & 5 & 3 & 3 \\
鲤科鱼类物种数百分比 M3 & 5 & 5 & 3 & 3 & 5 & 1 \\
鳑鮍亚科鱼类物种数百分比 M12 & 1 & 3 & 5 & 5 & 3 & 1 \\
耐受性强鱼类个体百分比 M17 & 3 & 1 & 5 & 3 & 3 & 1 \\
产漂流性卵鱼类物种数百分比 M24 & 5 & 3 & 3 & 5 & 3 & 1 \\
$I B I$ 总分 & 36.0 & 31.2 & 45.6 & 50.4 & 40.8 & 16.8 \\
$I B I$ 等级 & 差 & 差 & 一般 & 好 & 差 & 极差 \\
\hline
\end{tabular}

\section{2 参照点的选择}

参照点的选取对 $I B I$ 体系的构建起着导向性和决定性作用, 目前参照点的定义及其设定方法尚存在较 大争议, 参照点的选取原则是利用历史数据, 或者选择无人类干扰的河流原始河段作为参照点 ${ }^{[21]}$. 研究中选 取附近无农田分布、水质清澈、水生物丰富、船舶较少的观测点为参照点, 虽然综合考虑了河段历史数据、水 体的理化指标、周边土地利用、渔业捕捞压力等信息, 但选定的参照点是现有观测点中相对清洁的, 并非客 观状况, 可能导致评价结果与河流实际健康状况存在差异. 因此使用 $I B I$ 评价时, 为使评价结果更接近真实 状态, 应尽量使用历史记录, 此外历史数据还是指标设置和初步笁选重要依据. 陈桥等认为这样的参照点选 择方式对于制定区域分阶段污染控制或者生态恢复有一定的参考价值 ${ }^{[21]}$, 可以通过设定不同程度的参考状 态来定义不同恢复目标前提下的健康状况. 因此本文从生态环境逐步改善的环境考核机制的角度, 促进了 水生生物完整性评价河流健康在较大尺度上的推广与应用.

\section{$3.3 I B I$ 的选取与篮选}

自 Karr 等首次提出 12 项评价指标以来 ${ }^{[2]}$, 由于地域差异和生态系统类型不同已经发展为多种形式. $I B I$ 评价法在应用时要尽量保证初选指标设置的全面性, 以防止遗漏能够体现群落变化的关键指标. 本文根 据鉴江的情况进行适当调整, 根据各指标的采用率、功能特征分析及调查结果在河段间的差异, 最终选出具 有较高关注度、对环境敏感的 26 个指标. 指标篮选方法尚未形成统一, 如刘恺等根据指标属性分类篮选适 合广西河池地区的 $I B I$ 评价体系 ${ }^{[15]}$, 苏玉等研究滇池流域河流时采用 Barbour 评价方法对候选指标进行分 布范围、判别能力和 Pearson 相关性分析 ${ }^{[22]}$. 本文结合两种方法对候选指标依次进行属性分类篮选和 Barbour 评价方法以篮选鉴江河流健康主评指标 ${ }^{[23]}$, 评价指标由 26 个精简到 5 个, 确保反映的信息彼此相对独 
立, 评价指标对外界干扰足够敏感, 进而准确直观地反映生物完整性的变化. 虽然属性分类篮选和 Barbour 评价方法分别从不同侧面对生态系统健康和功能进行评价,但两者在理论和方法上相似, 把两者结合起来 用于指标篮选评是非常必要和可行的.

\section{$3.4 I B I$ 评价法的展望}

鱼类作为生物学评估监测的理想工具有其不可替代的优势:生活史长,生活范围广泛,受物理、化学及 生物条件长期的影响 ${ }^{[24]}$; 个体相对较大, 容易为人们识别, 作为评估要素比较直观; 分类系统完善, 生活史、 地理分布、环境耐受习性等方面的文献积累丰富,易于分析和解释. 本文从鱼类角度客观评价鉴江流域生态 环境现况,采用一个相对系统的篎选方法,构建了适合该地区的鱼类生物完整性评价体系,评价结果表明大 多数河段的生物完整性等级均为差和极差, 需采取一定措施对其进行生态修复以期恢复到相对健康的状 态. 为了进一步对鉴江流域环境进行评价和监测, 促进鱼类生物完整性评价河流健康的推广与应用,还应增 加不同季节、不同年度采样调查的次数, 从而进行更加准确的季节性和年度连续变化的研究, 同时应深人研 究生物完整性与环境因子之间的关系,以完善生物完整性评价体系.

\section{4 参考文献}

[1 ] 吴中华,于 丹,涂芒辉等. 汉江水生植物多样性研究. 水生生物学报, 2002,26(4):348-355.

[ 2 ] Karr JR, Dudley DR. Ecological perspective on water quality goals. Environmental Management, 1981, 5:55-68.

[ 3 ] 郑海涛.怒江中上游鱼类生物完整性评价 [学位论文].武汉:华中农业大学, 2006:1-10.

[ 4 ] 渠晓东, 刘志刚, 张 远. 标准化方法笁选参照点构建大型底栖动物生物完整性指数. 生态学报, 2010,32(15): $4661-4672$.

[ 5 ] Oberdorff T, Hughes RM. Modification of an index of Biotic Integrity based on fish assemblages to characterize rivers of the Seine Basin, France. Hydrobiologia, 1992, 228(2):117-130.

[ 6 ] Bozzetti M, Schulz UH. An indes of biotic ingtegrity based on fish assemblages for subtropical stream Brazil. Hydrobiologia, 2004, 529:133-144.

[ 7 ] 刘明典,陈大庆,段辛斌等. 应用鱼类生物完整性指数评价长江中上游健康状况. 长江科学院院报, 2010,24(12): $1-10$.

[ 8 ] 裴雪姣,牛翠娟,罗 静等. 应用鱼类完整性评价体系评价辽河流域健康. 生态学报, 2010,30(21):5736-5746.

[9] 黄亮亮,吴志强,蒋 科等. 东芳溪鱼类生物完整性评价河流健康体系的构建与应用. 中国环境科学, 2013,7: 1280-1289.

[10］翟家齐,左其亭. 鉴江流域水安全问题及人类活动影响分析. 水资源与水工程学报, 2008,19(1):7-11.

[11] Karr JR, Chu EW. Sustaining living rivers. Hydrobiologia ,2000, 422/423:1-14.

[12] 潘畑华.广东淡水鱼类志.广东:广东科学技术出版社, $1991: 1-589$.

[13] 乐佩琦. 中国动物志: 硬骨鱼纲・鲤形目・下卷. 北京:科学出版社, 2000:1-531.

[14] Karr JR. Biological integrity: A long-neglected aspect water resource management. Ecological Applications, 1991,(1): 66-84.

[15] 刘 恺, 周 伟, 李风莲等. 广西河池地区河流基于鱼类的生物完整性指数篮选及其环境质量评估. 动物学研究, $2010, \mathbf{3 1}(5): 531-538$.

[16] Karr JR. Ecological integrity and ecological health are not the same. In: Schulze P ed. Engineering within ecological constraints. National Academy of Engineering: National Academy Press, 1995: 97-109.

[17] Blocksom KA, Kurtenbach JP, Klemm DJ et al. Development andevaluation of the LMII for New Jersey lakes and reservoirs. Environmental Monitoring and Assessment, 2002, 77:311-333.

[18] 朱 迪,常剑波. 长江中游浅水湖泊生物完整性时空变化. 生态学报,2004,24(12):2762-2766.

[19] Moyle PB, Randall RJ. Evaluating the biotic integrity of watersheds in Sierra Nevala California. Conservation Biology, 1998, 12(6):1318-1326.

[20] 刘家福. 鉴江流域水文特性分析初探. 广东水利水电,2002,(6):33-35.

[21] 陈 桥, 徐东昫, 张 翔等. 太湖流域平原水网区底栖动物完整性健康评价. 环境科学研究, 2013, 26 (12): 1301-1308.

[22] 苏 玉, 曹晓峰, 黄 艺. 应用底栖动物完整性指数评价滇池流域人湖河流生态系统健康. 湖泊科学, $2013,25(1)$ : 91-98.

[23] 冯 彦,何大明,杨丽萍. 河流健康评价的主评指标篮选. 地理研究, 2012,31(3):389-398.

[24] Karr JR. Assessment of biotic integrity using fish communities. Fisheries, 1981, 6(6) : 21-27. 